\title{
Research on Mobile E-commerce Model Oriented Manufacturing Service
}

\author{
Ping $\mathrm{Wu}^{1}$, Feng Xiong ${ }^{1}$, Qianqian $\mathrm{Cao}^{2}$ \\ ${ }^{1}$ Cims \& Robot Center, Shanghai University, Shanghai, China \\ ${ }^{2}$ E-Commerce Center, CHINA MOBILE Shanghai, China \\ wuping526@163.com
}

\begin{abstract}
With the arrival of the era of the Internet of Things, as well as the development of intelligent terminals and mobile Internet, manufacturing informationization has new requirements. The emergence of mobile e-commerce fits the requirements well and can enhance the control of manufacturing companies on the market and adaptability. In this article, the mobile Internet will be integrated into the key sector of manufacturing, then we take the advantage of mobile communication without being limited by the space and time to break the wired transfer pattern, realize informationization ubiquitous coverage and omnipotent applications in manufacturing companies, and promote the enterprise from the simple horizontal applied to complex vertical represented by CRM and ERP applications.
\end{abstract}

Index Terms - manufacturing informationization, intelligent terminals, mobile e-commerce

\section{Introduction}

Manufacturing which is the core of our national economy, the driving force of industrialization and a pillar industry of the national economy has a complex unit size that constitutes the industrial chain, extensive distribution channels and the flood of information, all these make the management and coordination of the information difficult. With the change in the competitive situation, the manufacturing faces multifaceted challenges such as the cost, technology and management. The ability of information flow integrated and coordinated with logistics, fund-flow has become the manufacturing industry "bottleneck". For example, in the traditional information systems, data-in generally includes identification, cleaning and personal labor input three aspects, the process is cumbersome and cannot be synchronized. It appears in a large number of order entries, purchasing storage, product storage and so on. ERP itself does not automatically recognize this job information, therefore a gap between the logistics of ERP and information is caused[2]. The best way to solve that is combined with a mobile communication network, terminal identification and other advanced technologies.

In addition, the manufacturing production pattern is from flow line production transition to order and even mass customization phase, in order to quickly seize the market, meet consumer diversified and personalized needs, the companies are required to rapidly grasp the sales and order information for timely adjustment of production and supply. Combined with the high-end technology as mobile communication network and smart mobile terminals, the manufacturing could make information flow to promote fund-flow and logistics efficient circulation and reduce the uncertainty caused by the delay information. It can also improve production efficiency while maintaining quality through timely response to business processes.

\section{Manufacturing Mobile E-commerce Model Building[1]}

Manufacturing a wide variety, are classified into the mode of industry whose driving force is order-pulled under the support of information system, the cooperation of logistics network and financial institutions. The main members of supply chain include the suppliers, the manufacturers, the distributors and the users, its core business can be summarized as purchasing, production, sales and after-sales service, etc. In this paper, iron and steel, automobile are mainly introduced as large manufacturing. Its overall model is shown in figure 1.

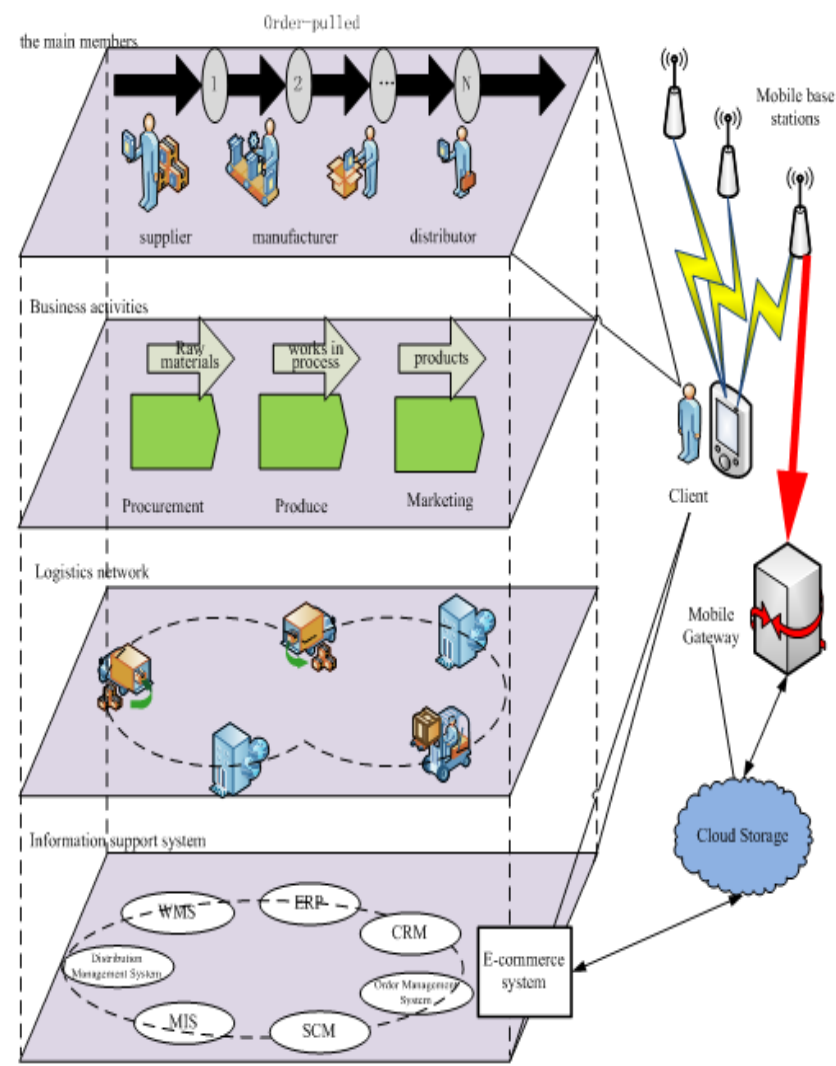

Fig.1 The overall model of manufacturing system. 
This article is mainly around the business activities module of the overall model, with its core business as the main line. Data transmission is implemented through the mobile communication network and various business activities are carried out at any time and place by using mobile terminals, and the cloud storage is also achieved, so as to cover the whole process such as purchasing, production and sales, providing customers with the satisfaction of needs of a comprehensive service.

\section{A. Based on the procurement of mobile e-commerce model[3]}

From the overall perspective, manufacturing enterprise procurement is the starting point of product produced by the enterprise value-added process, as well as an end of the enterprise core business processes. Procurement costs, on the other hand, now account for $50 \% \sim 70 \%$ of the total costs of manufacturing enterprises, and with the development of the supply chain and the depth of outsourcing, the proportion is still rising. Statistics show that if the purchasing saves $1 \%$, the corporate profits will increase by $5 \% \sim 10 \%$ [4]. The stand or fall of business process, thus, is the key that affects manufacturing enterprise cost reduction, operational efficiency promotion. But there still exist many problems in current procurement procedures, such as preparation of purchase order can't be lived, resulting in business processing delay; quotes from suppliers cannot get online timely response; goods cannot live scan and acceptance, etc.

In order to solve the above problems, the method of embedding mobile information terminal in purchasing activities will be used in the paper (see figure 2), to implement business requirements of the scene processing, timely response and intelligent acceptance and so on.

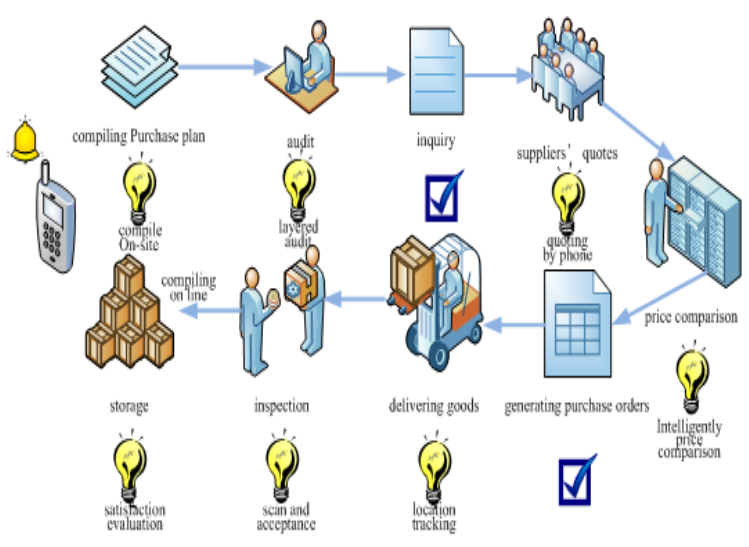

Fig.2 The procurement business processes combined phone.

\section{B. Based on the production of mobile e-commerce model}

In actual production, the products require an orderly coordination and administration as well as the equipments and personnel; however, traditional way of on-site management is time-consuming and inefficient. By adding mobile phones, mobile communication network into the production process, it can not only shorten the time of on-site coordination management, improve the efficiency of coordination management, scientifically deploy production business, also do protective treatment timely by perceiving security risks in advance. As for production safety, you can use dynamic prestored technology and the function module of USB plug-in to collect and monitor the real-time information in high energy consumption or high pollution processes or high accident area, once a security risk appears, the related video information is transmitted to the administrator's mobile terminal in time, the administrator could use mobile terminal to set parameters and send instructions to handle security hidden danger timely and effectively. Moreover, the mobile terminal and network also can apply to parts-scheduling-orientated production process management and storage and transportation that people and vehicles positioned scheduling are orientated[4].

\section{Based on the marketing of mobile e-commerce model[5]}

The equations are an exception to the prescribed specifications of this template. You will need to determine whether or not your equation should be typed using either the Times New Roman or the Symbol font (please no other font). To create multileveled equations, it may be necessary to treat the equation as a graphic and insert it into the text after your paper is styled.

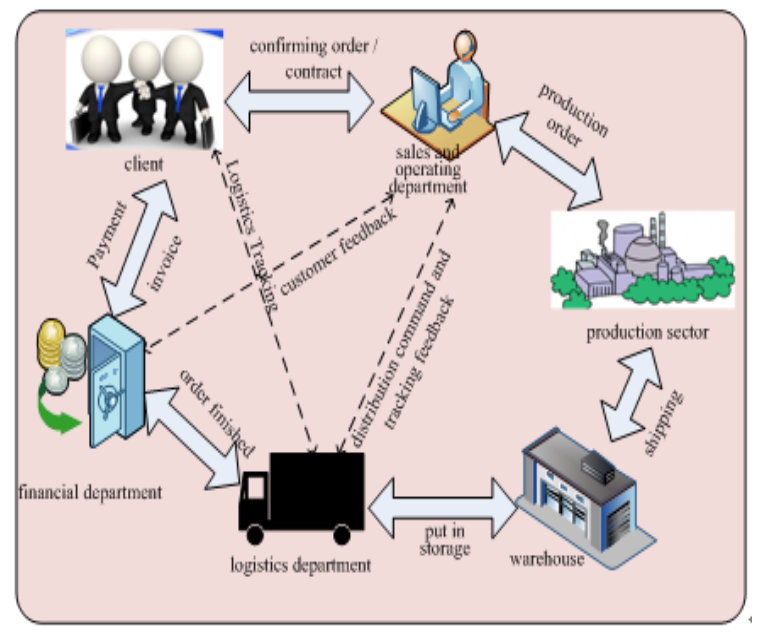

Fig.3 The manufacturing sales order process.

The marketing of manufacturing industry chain is the whole process of beginning with making the enterprise sales plan, acquiring sales orders, finally ending with customers getting the products(see figure 3). But at present there are disadvantages in marketing business, for example, business processing is delayed because a salesman visit customers, and cannot achieve the orders and the information feedback on-site; the salesperson misses sales opportunities on account of the boss on a business trip so that the important marketing plan cannot be approved in OA and so on. Therefore, rapidly and timely mobile marketing become a demand to the further development of enterprises.

Mobile marketing means that the enterprises utilize mobile terminal equipment to carry out interactive marketing 
activities, based on mobile communication network, and combining the traditional Internet, with quick, direct, interactive, personalized and focus, orientation, accurate characteristics, it can give users a better experience, and meet the consumers' needs anytime and anywhere[5]. The applications of mobile marketing business is shown in figure 4, integrating with SCM, it can achieve plan orders, order confirmation and notify, etc; integrating with DRP, it can implement plan upload, contract tracking, shipment, new product releases and so on, thus it could carry out a new sales and promotion channels.

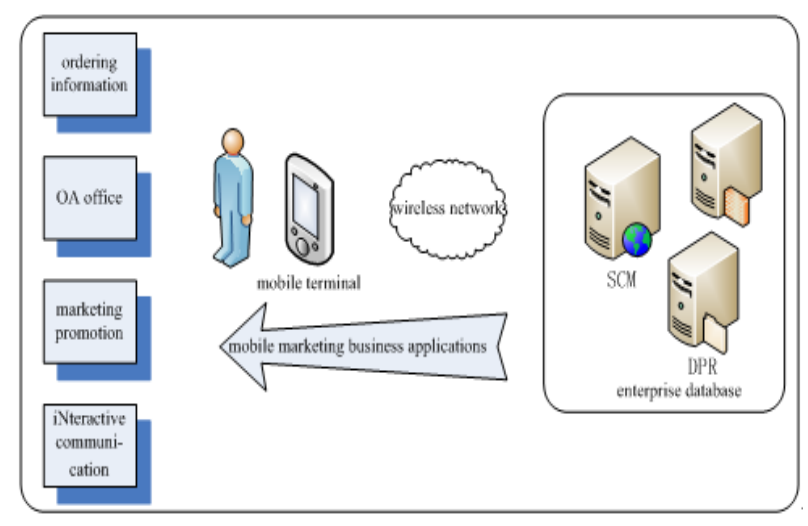

Fig.4 Mobile marketing business applications.

\section{Mobile OA Application Status}

Mobile OA is specifically tailored for enterprises office automation system that generally meets the most basic, essential and commonly used office automation needs. The product has been running on the line, and running in good condition. Through the implementation of the project, it further accelerates the enterprise information technology, improves the work efficiency. For China Mobile in Shanghai, its achievements and benefits are mainly embodied in the following aspects:

1) Business processing in course of moving, expands the office space and improves the efficiency of business processing.
2) Accessing to the internal network database to edit documents reduces office costs and improves office efficiency.

3) The scope of its use is extensive, you can do mobile office at any time and in any place.

4) The system is security and stable, it uses 256-bit key for the data transmission encryption, the Mobile communication network is for data transfer only.

The product has multi-dimensional and multi-kinds of functions. It is highly modular of functional information, simple operation, user-friendly office anytime, anywhere via mobile phone. In the process of enterprise informationization, the mobile office will become the mainstream of social development.

\section{Conclusions}

This article based on manufacturing industry's characteristics integrates the mobile internet and mobile terminals into the core manufacturing business units (such as procurement, processing, marketing, etc.) to break the traditional model constrained by the limitations of time and space, allow customers to virtually make business anywhere and anytime. It brings convenience to clients with promoting the companies of business processes in real-time supervision and management. Besides, after the application and promotion of manufacturing mobile e-commerce model, it will also promote the CHINA MOBILE own business (such as mobile terminals, traffic, SMS, video, etc.) to increase and achieve win-win situation between enterprises.

\section{References}

[1] Yaming Zhang and Haiou Liu, "The innovation research of mobile ecommerce industry application mode," J. Enterprise Economy, pp. 59-62,2011.

[2] Xiaohong Wang, Yu Chen and Yanan Li, "The applications of ERP mobile office system," J. Technology Wind, pp.18-19,2011.

[3] Junyan Wu, "Company A's Product Localization Project Procurement Management Research," D. East China University of Science and Technology,2007.

[4] Haihui Gao, Kebin Jia, Xiaohong Bao and Jie He, "Research on implementation and key technologies of the vehicle monitor system based on LBS," J. Telecommunications Science, pp.67-71,2009.

[5] Weihong Liao, "The Practical Analysis on the Interactive Marketing Mode in Mobile E-commerce," J. China Business and Market, pp. 8589, 2012. 